\title{
Bond strength and solubility of a novel polydimethylsiloxane-gutta-percha calcium silicate-containing root canal sealer
}

\section{Wytrzymałość wiązania oraz rozpuszczalność nowego uszczelniacza kanałowego zawierającego polidimetylosiloksan-gutaperkę i krzemian wapnia}

\author{
Mennatullah Mohammed Khalili,A,C-F, Mai Hisham Abdelrahman ${ }^{2, A, E, F}$, Sara El-Mallah ${ }^{3, A, B, F}$ \\ ${ }^{1}$ Department of Dental Biomaterials, Faculty of Dentistry, Fayoum University, Egypt \\ ${ }^{2}$ Department of Dental Biomaterials, Faculty of Dentistry, Modern Science and Arts University, Cairo, Egypt \\ ${ }^{3}$ Department of Endodontics, Faculty of Dentistry, Fayoum University, Egypt \\ A - research concept and design; $B$ - collection and/or assembly of data; $C$ - data analysis and interpretation; \\ $D$ - writing the article; $E$ - critical revision of the article; $F$ - final approval of the article
}

Address for correspondence

Mennatullah Mohammed Khalil

E-mail: mml11@fayoum.edu.eg

\section{Funding sources}

None declared

Conflict of interest

None declared

Received on February 14, 2019

Reviewed on February 17, 2019

Accepted on March 14, 2019

Published online on June 28, 2019

Cite as

Khalil MM, Abdelrahman MH, El-Mallah S. Bond strength and solubility of a novel polydimethylsiloxane-guttapercha calcium silicate-containing root canal sealer. Dent Med Probl. 2019;56(2):161-165. doi:10.17219/dmp/105626

DOI

$10.17219 / \mathrm{dmp} / 105626$

Copyright

○ 2019 by Wroclaw Medical University

This is an article distributed under the terms of the

Creative Commons Attribution 3.0 Unported License (CC BY 3.0)

(https://creativecommons.org/licenses/by/3.0/)

\begin{abstract}
Background. Endodontic sealers are essential for sealing gutta-percha to the dentin walls. They help to ensure that the canal remains free of microorganisms which might lead to infection. In order to perform their intended function, the sealers should properly adhere to the dentin walls and remain insoluble when set in the canal.

Objectives. The purpose of this study was to evaluate the bond strength and solubility of a novel polydimethylsiloxane-gutta-percha calcium silicate-containing root canal sealer (GuttaFlow ${ }^{\circledR}$ bioseal) and compare it with the zinc oxide and eugenol sealer (Zica $\left.{ }^{\circledR}\right)$.

Material and methods. The endodontic sealers used in this study were GuttaFlow bioseal and Zical. The bond strength was assessed using push-out bond strength test in 3 root segments: coronal, middle and apical. The solubility was tested according to the American National Standards Institute / American Dental Association (ANSI/ADA) specification No. 57 at 3 different time intervals: 1,7 and 14 days.

Results. The push-out bond strength in all root segments was significantly higher in Zical compared to GuttaFlow bioseal. The solubility was significantly higher on day 1 and 7 in Zical compared to GuttaFlow bioseal, and on day 14, the difference between them was not significant.

Conclusions. Within the limitations of this study, the endodontic sealer Guttaflow bioseal showed low bond strength values compared to Zical. The solubility of the set GuttaFlow bioseal and Zical were both within the recommended ANSI/ADA levels.

Key words: solubility, GuttaFlow bioseal, polydimethylsiloxane-guttapercha sealer, calcium silicate-containing sealer, push-out bond strength

Słowa kluczowe: rozpuszzzalność, GuttaFlow bioseal, gutaperka na bazie polidimetylosiloksanu, uszczelniacz na bazie krzemianu wapnia, wytrzymałość wiązania w teście wypychania
\end{abstract}




\section{Introduction}

Endodontic treatment is a 3-step process consisting of proper cleaning, shaping and obturating the root canal. ${ }^{1}$ The most common method of obturation consists in using gutta-percha combined with a sealer. ${ }^{2}$ The main function of the sealer is to fill the spaces between the core material and the walls of the root canal in an attempt to form a coherent mass of the obturating material. Numerous sealers with different properties are used; one of the oldest sealers is the zinc oxide and eugenol sealer, which is popular among clinicians, despite its limitations. ${ }^{3}$ GuttaFlow $^{\circledR}$ bioseal (Coltène/Whaledent AG, Altstätten, Switzerland) is a novel polydimethylsiloxane-gutta-percha calcium silicate-containing root canal sealer that obturates the root canal and has tissue-repairing properties due to the presence of calcium silicate. ${ }^{4,5}$

The bond strength of the obturating material to the intraradicular dentin is an important property to be assessed when evaluating an endodontic sealer. The ability of a root canal sealer to adhere to the dentin is essential in maintaining the integrity of the sealer-dentin interface while undergoing mechanical stresses. ${ }^{6-8}$ It may also be indicative of the ability to prevent bacterial microleakage, creating a favorable environment for periapical repair and avoiding reinfection. ${ }^{9-11}$

Solubility is another crucial property of sealers, because it may compromise the quality and success of the endodontic treatment. Low solubility is one of the requirements for endodontic sealers according to the American National Standards Institute / American Dental Association (ANSI/ADA) specification No. 57. ${ }^{12}$

The aim of this study was to assess the bond strength and solubility of a novel polydimethylsiloxane-guttapercha calcium silicate-containing root canal sealer and compare it with the zinc oxide and eugenol sealer.

\section{Material and methods}

Two root canal sealers, GuttaFlow bioseal and Zical ${ }^{\circledR}$ (Prevest DenPro Ltd., Jammu, India), were tested in this study. Table 1 shows the chemical composition of the tested sealers.

\section{Push-out bond strength test}

A total of 14 single-rooted human teeth were used in this study. The inclusion criteria for the selected teeth were as follows: free from root decay, root fracture or any other root defect. The teeth were stored as anonymous specimens in $0.1 \%$ thymol solution and were used within 3 months of storage. The teeth were collected on October $6^{\text {th }}$ from patients undergoing routine dental treatment at the Oral and Maxillofacial Department at Modern Science and Arts University, Egypt, and kept for research purposes with the patient's prior knowledge before treatment.

The crowns were removed at the cementoenamel junction using a water-cooled precision microsaw (IsoMet ${ }^{\circledR}$ 4000; Buehler, Lake Bluff, USA). The working length was determined using an initial K-file size 15 (Mani Inc., Tochigi, Japan) to reach the apical foramen, and then subtracting $1 \mathrm{~mm}$.

The preparation was carried out using the crown-down technique. All root canals were instrumented using ProTaper $^{\circledR}$ rotary $\mathrm{Ni}-\mathrm{Ti}$ instruments (Dentsply Maillefer, Ballaigues, Switzerland), starting with SX (0.19/0.04), followed by S1 (0.18/0.02), S2 (0.20/0.04), F1 (0.20/0.07), F2 $(0.25 / 0.08)$, and F3 (0.30/0.09). The apical patency was checked using a patency file after each file.

The canals were irrigated after using each instrument with $5 \mathrm{~mL}$ of a freshly prepared solution of $2.5 \%$ sodium hypochlorite $(\mathrm{NaOCl})$. Irrigation was performed using 5-milliliter disposable plastic syringes with 27-gauge needle tips placed passively into the canal, up to $3 \mathrm{~mm}$ from the apical foramen without binding. The canals were then dried with sterile paper points and the teeth were randomly divided into 2 groups $(n=7)$.

A trial fit of the ProTaper universal gutta-percha points size F3 was performed in all samples. The sealers were freshly prepared according to the manufacturer's instructions. Zical was applied to the canal walls with a Lentulo filler, which was then used to coat gutta-percha. The sealer-coated gutta-percha was placed in the canal space up to the working length. GuttaFlow bioseal was injected into the canal space using the tip provided by the manufacturer. The master cone was then coated with the sealer and seated inside the canal. Excess gutta-percha was removed using a heat carrier and gutta-percha was vertically compacted at the canal orifice.

The obturated teeth were embedded in chemicallycured acrylic resin and left to set. On the acrylic resin, the coronal, middle and apical thirds were defined and a section of $2 \mathrm{~mm}$ in thickness was cut from the center of each third using a water-cooled precision microsaw (IsoMet 4000). This resulted in 3 slices in each sample and 21 slices in each group.

Table 1. Characteristics of the tested endodontic sealers

\begin{tabular}{|c|c|c|}
\hline Commercial name & Manufacturer & Composition \\
\hline GuttaFlow bioseal & $\begin{array}{c}\text { Coltène/Whaledent AG, } \\
\text { Altstätten, Switzerland }\end{array}$ & $\begin{array}{r}\text { gutta-percha powder particles, polydimethylsiloxane, platinum catalyst, zirconium dioxide, } \\
\text { calcium salicylate, nano-silver particles, coloring, bioactive glass-ceramic }\end{array}$ \\
Zical & $\begin{array}{c}\text { Prevest DenPro Ltd., } \\
\text { Jammu, India }\end{array}$ & powder: zinc oxide, bismuth subcarbonate, barium sulfate, sodium borate, iodoform \\
and hydrogenated resin; liquid: eugenol
\end{tabular}


The filling material was then loaded with a stainless steel plunger of a 0.9 -millimeter diameter. The plunger was mounted on the upper part of a universal testing machine (model 3345; Instron ${ }^{\circledR}$, High Wycombe, UK) and the data was recorded using computer software (Bluehill ${ }^{\circledR} 3$, v. 3.3; Instron). The tests were conducted at a crosshead speed of $0.5 \mathrm{~mm} / \mathrm{min}$ using a load cell of $500 \mathrm{~N}^{10,13,14}$

The area under load was calculated as follows:

area $=$ circumference of restoration $\times$ thickness.

The push-out value in $\mathrm{MPa}$ was calculated from the force in $\mathrm{N}$ divided by area in $\mathrm{mm}^{2}$.

\section{Solubility test}

The solubility test was conducted according to ANSI/ ADA specification No. 57. ${ }^{12}$ Split ring molds, 1.5 -millimeter-thick with an inner diameter of $20 \mathrm{~mm}$, were used. The rings were filled with the sealers and supported by a glass plate covered with a cellophane sheet. They were then placed in an incubator $\left(37^{\circ} \mathrm{C}, 95 \%\right.$ relative humidity) for a period corresponding to 3 times the setting time. The sealers were removed from the mold and weighed 3 times with an accuracy of $0.001 \mathrm{~g}$. Each specimen was suspended from a string of dental floss and the floss was fixed to the stopper of a glass bottle $(\sim 40 \mathrm{~mm}$ in diameter). The bottle was then filled with $50 \mathrm{~mL}$ of distilled water $\mathrm{pH} \sim 5.8$.

The bottles were stored for 1 week in an incubator $\left(37^{\circ} \mathrm{C}, 95 \%\right.$ relative humidity). The samples were rinsed with distilled water, and then blotted dry with absorbent paper. They were placed in desiccators for $24 \mathrm{~h}$, and then reweighed. Seven samples for each sealer were tested at 3 time intervals: 1, 7 and 14 days. The weight loss of each sample (initial mass minus final mass), expressed as the percentage of the original mass, was recorded as the solubility of the sealer. ${ }^{15}$

\section{Statistical analysis}

Statistical analysis was performed using the commercially available software program PASW Statistics for Windows, v. 18.0 (SPSS Inc., Chicago, USA). Data was

Table 2. Mean values of push-out bond strength in each root segment [MPa]

\begin{tabular}{|c|c|c|c|}
\hline Root segment & Endodontic sealer & Mean $\pm S D$ & $p$-value \\
\hline \multirow{2}{*}{ Coronal } & GuttaFlow bioseal & $1.690^{c 1} \pm 0.022$ & \multirow{2}{*}{$0.000^{*}$} \\
\hline & Zical & $4.254^{\mathrm{b} 2} \pm 0.017$ & \\
\hline \multirow{2}{*}{ Middle } & GuttaFlow bioseal & $2.077^{\mathrm{b} 1} \pm 0.129$ & \multirow{2}{*}{$0.000^{*}$} \\
\hline & Zical & $4.360^{\mathrm{b} 2} \pm 0.022$ & \\
\hline \multirow{2}{*}{ Apical } & GuttaFlow bioseal & $2.374^{\mathrm{a} 1} \pm 0.017$ & \multirow{2}{*}{$0.000^{*}$} \\
\hline & Zical & $7.300^{\mathrm{a} 2} \pm 0.022$ & \\
\hline
\end{tabular}

SD - standard deviation; * statistically significant; means sharing the same superscript letter and number are not significantly different. expressed as mean and standard deviation, and the significant differences between the groups were compared using the independent $t$-test. Within the same sealer group, different root segments and different time observations were evaluated in terms of push-out bond strength and solubility, respectively, using the one-way analysis of variance (ANOVA), followed by Tukey's post hoc test when ANOVA revealed a significant difference. The level of significance was set at $p<0.05$.

\section{Results}

The results are presented in Tables 2 and 3. GuttaFlow bioseal showed significantly lower push-out bond strength in all 3 segments compared to Zical. The apical segments in both groups showed higher bond strength, followed by the middle and coronal segments, and there was no significant difference between the middle and coronal segments in Zical (Table 2). GuttaFlow bioseal showed lower solubility compared to Zical on days 1, 7 and 14, with no significant difference in both groups on day 14. In GuttaFlow bioseal there was no significant difference in solubility with time, whereas in Zical there was a significant increase in solubility after 14 days (Table 3 ).

\section{Discussion}

Sealers are of crucial importance in the obturation process and can affect the quality of the endodontic treatment. Zinc oxide and eugenol sealers have represented the golden standard in endodontic treatment for many years due to their long history of successful use. ${ }^{2,16}$ Recently, traditional sealers are being replaced with new sealers with more favorable properties; one of these new endodontic sealers is GuttaFlow bioseal. It is an intelligent obturating material that seals and fills the root canal. Upon contact with fluids, the bioactive material provides calcium silicate that forms hydroxyapatite crystals on the surface to improve adhesion and provide repair. ${ }^{4,5}$

In the obturation of the cleaned and shaped canal, the most common technique is cold lateral compaction.

Table 3. Mean values of solubility at each observation time [\%]

\begin{tabular}{|l|c|c|c|}
\hline \multicolumn{1}{|c|}{ Time } & Endodontic sealer & Mean \pm SD & $p$-value \\
\hline \multirow{2}{*}{1 day } & GuttaFlow bioseal & $0.724^{\mathrm{a} 1} \pm 0.081$ & \multirow{2}{*}{$0.002^{*}$} \\
\hline \multirow{2}{*}{7 days } & Zical & $0.874^{\mathrm{a} 2} \pm 0.036$ & \\
& GuttaFlow bioseal & $0.697^{\mathrm{a} 1} \pm 0.098$ & \multirow{2}{*}{$0.014^{*}$} \\
\hline \multirow{2}{*}{14 days } & Zical & $0.823^{\mathrm{a} 2} \pm 0.046$ & \\
& GuttaFlow bioseal & $0.661^{\mathrm{a} 1} \pm 0.101$ & \multirow{2}{*}{0.068} \\
\hline
\end{tabular}

* statistically significant; means sharing the same superscript letter and number are not significantly different. 
This technique has limitations, which include the following: poor adaptation of gutta-percha to the canal walls, spaces between gutta-percha and the sealer, and the presence of a large amount of the sealer in the apical region due to the inhomogeneous gutta-percha-sealer mass. ${ }^{17}$ To help to overcome these limitations, the technique used in this study was the single-cone technique. A single gutta-percha master cone placed with a sealer provides a final compact mass without spaces. ${ }^{18}$

Ideal adhesion of the root canal filling material to the root dentin is one of the main criteria in evaluating the clinical efficacy of the obturation technique. ${ }^{17}$ It helps to maintain the integrity of the dentin-sealer interface by resisting dislodgment and ensuring the proper function of the restored tooth. ${ }^{4}$ The adhesion of the obturating material to the dentin walls is evaluated using bond strength testing. One of the most reproducible and reliable bond strength testing techniques is the push-out method. It simulates shear stresses present during functioning and the fracture of the samples occurs parallel to the dentin-bonded surface, making it a true shear test. This testing method also has an added advantage - it allows the evaluation of the bond strength in different root segments. ${ }^{14,19,20}$

In this study, the bond strength of Zical was significantly higher compared to GuttaFlow bioseal in all root segments. In both materials, the bond strength was the highest in the apical segment, followed by medium and the lowest bond strength, which was found coronally. The difference between all segments was statistically significant except between the middle and coronal segments in Zical. There is no agreement among authors on how the location of the root dentin segment affects the bond strength. Similarly to this study, Uppalapati and Mandava and Sly et al. found that the bond strength increases from the coronal to the apical direction. ${ }^{21,22}$

The low bond strength values of GuttaFlow bioseal could be due to the presence of calcium silicate in the sealer in the absence of moisture. ${ }^{23}$ According to Nagas et al., mineral trioxide aggregate (MTA), a calcium silicatebased material, requires moisture during setting to reach high strength values and resist dislodgment forces. ${ }^{24}$ Sarkar et al. and Prüllage et al. attributed the low bond strength values of the MTA-based sealers in their studies to the absence of phosphate-containing fluid. ${ }^{25,26}$ Such fluids cause the release of the calcium and hydroxyl ions from the sealer and upon release of these ions, tag-like structures extend into the dentin and increase the adhesion of these sealers. Another reason for the low bond strength of GuttaFlow bioseal could be the low adhesion capacity of the tag-like structures produced by calcium silicate present in the sealer. ${ }^{27}$

Another essential property of endodontic sealers is solubility, because if dissolved, they may release chemicals into the periapical tissues, which could trigger an inflammatory response. The dissolution of the sealer may also result in a gap between the root canal dentine and the filling material, increasing leakage over time. ${ }^{28,29}$ According to ANSI/ADA specification No. 57, the solubility of set sealers should not exceed 3\% mass fraction after immersion in water for $24 \mathrm{~h} .{ }^{12}$ In both sealers, the solubility did not exceed the recommended amount over all tested time periods. The solubility of both sealers was the highest on day 1 and decreased on day 7 and 14. Comparing the 2 sealers, the solubility of Zical was higher than that of GuttaFlow bioseal at all 3 time intervals, but on day 14 , the difference between both groups was not significant. The higher solubility of Zical could be related to the hydrolysis reaction of the zinc eugenolate, which is essential for setting. It could also be due to the unreacted eugenol escaping from the set cement. ${ }^{30}$ The solubility of GuttaFlow bioseal could result from the presence of calcium silicate and its solubility, according to Hoikkala et al. ${ }^{15}$ Biomineralization requires the dissolution of the sealer to provide the solution with ions needed for mineralization. Therefore, in the case of GuttaFlow bioseal, the solubility could be considered positive to allow ion release and hydroxyapatite formation on the dentin surface.

\section{Conclusions}

Within the limitations of this study, the endodontic sealer GuttaFlow bioseal showed low bond strength values compared to Zical. The solubility of the set GuttaFlow bioseal and Zical were both within the recommended ANSI/ADA levels.

\section{ORCID iDs}

Mennatullah Mohammed Khalil (D) https://orcid.org/0000-0002-4944-7415 Mai Hisham Abdelrahman (D) https://orcid.org/0000-0003-4934-6064 Sara El-Mallah (D) https://orcid.org/0000-0003-2050-5877

\section{References}

1. Camargo RV, Silva-Sousa YTC, Rosa RPFD, et al. Evaluation of the physicochemical properties of silicone- and epoxy resin-based root canal sealers. Braz J Oral Res. 2017;31:e72.

2. Ørstavik DA. Materials used for root canal obturation: Technical, biological and clinical testing. Endod Topics. 2005;12(1):25-38.

3. Kaur A, Shah N, Logani A, Mishra N. Biotoxicity of commonly used root canal sealers: A meta-analysis. J Conserv Dent. 2015;18(2):83-88.

4. Akcay M, Arslan H, Durmus N, Mese M, Capar ID. Dentinal tubule penetration of $\mathrm{AH}$ Plus, iRoot SP, MTA fillapex, and guttaflow bioseal root canal sealers after different final irrigation procedures: A confocal microscopic study. Lasers Surg Med. 2016;48(1):70-76.

5. Gandolfi MG, Siboni F, Prati C. Properties of a novel polysiloxaneguttapercha calcium silicate-bioglass-containing root canal sealer. Dent Mater. 2016;32(5):e113-e126.

6. Huffman BP, Mai S, Pinna L, et al. Dislocation resistance of ProRoot Endo Sealer, a calcium silicate-based root canal sealer, from radicular dentine. Int Endod J. 2009;42(1):34-46.

7. Rached-Junior FJ, Souza-Gabriel AE, Alfredo E, Miranda CE, SilvaSousa YT, Sousa-Neto MD. Bond strength of Epiphany sealer prepared with resinous solvent. J Endod. 2009;35(2):251-255.

8. Saleh IM, Ruyter IE, Haapasalo MP, Orstavik D. Adhesion of endodontic sealers: Scanning electron microscopy and energy dispersive spectroscopy. J Endod. 2003;29(9):595-601. 
9. Albino Souza M, Dalla Lana D, Gabrielli E, Barbosa Ribeiro M, Miyagaki DC, Cecchin D. Effectiveness of final decontamination protocols against Enterococcus faecalis and its influence on bond strength of filling material to root canal dentin. Photodiagnosis Photodyn Ther. 2017;17:92-97.

10. Silva EJ, Carvalho NK, Prado MC, et al. Push-out bond strength of injectable pozzolan-based root canal sealer. J Endod. 2016;42(11):1656-1659.

11. Flores DS, Rached FJ Jr, Versiani MA, Guedes DF, Sousa-Neto MD, Pécora JD. Evaluation of physicochemical properties of four root canal sealers. Int Endod J. 2011;44(2):126-135.

12. American National Standards Institute / American Dental Association. Specification No. 57: Endodontic Sealing Materials. Chicago, IL : ANSI/ADA; 2000.

13. Upadhyay ST, Purayil TP, Ballal NV. Evaluation of push-out bond strength of GuttaFlow 2 to root canal dentin treated with different smear layer removal agents. Saudi Endod J. 2018;8(2):128-132.

14. Goracci C, Tavares AU, Fabianelli A, et al. The adhesion between fiber posts and root canal walls: Comparison between microtensile and push-out bond strength measurements. Eur J Oral Sci. 2004;112(4):353-361.

15. Hoikkala NJ, Wang X, Hupa L, Smått JH, Peltonen J, Vallittu PK. Dissolution and mineralization characterization of bioactive glass ceramic containing endodontic sealer Guttaflow Bioseal. Dent Mater J. 2018;37(6):988-994.

16. Demiryürek EO, Külünk $S$, Yüksel G, Saraç D, Bulucu B. Effects of three canal sealers on bond strength of a fiber post. $J$ Endod. 2010;36(3):497-501.

17. Mokhtari H, Rahimi S, Forough Reyhani M, Galledar S, Mokhtari Zonouzi HR. Comparison of push-out bond strength of gutta-percha to root canal dentin in single-cone and cold lateral compaction techniques with AH Plus sealer in mandibular premolars. J Dent Res Dent Clin Dent Prospects. 2015;9(4):221-225.

18. Samiei M, Aghazade M, Farhadi F, Shahveghar N, Torab A, Vahid Pakdel SM. Sealing efficacy of single-cone obturation technique with MTA and CEM cement: An in vitro bacterial leakage study. J Dent Res Dent Clin Dent Prospects. 2014;8(2):77-83.

19. Cecchin D, Souza M, Carlini-Júnior B, Barbizam JV. Bond strength of Resilon/Epiphany compared with gutta-percha and sealers Sealer 26 and Endo Fill. Aust Endod J. 2012;38(1):21-25.

20. Ertas H, Kucukyilmaz E, Ok E, Uysal B. Push-out bond strength of different mineral trioxide aggregates. Eur J Dent. 2014;8(3):348-352.

21. Uppalapati LV, Mandava J. Evaluation of push-out bond strengths of two different adhesive root canal obturation systems: An in vitro study. J Dr NTR Univ Health Sci. 2012;1(2):111-115.

22. Sly MM, Moore BK, Platt JA, Brown CE. Push-out bond strength of a new endodontic obturation system (Resilon/Epiphany). J Endod. 2007;33(2):160-162.

23. Donnermeyer D, Dornseifer P, Schäfer E, Dammaschke T. The pushout bond strength of calcium silicate-based endodontic sealers. Head Face Med. 2018;14(1):13.

24. Nagas E, Uyanik MO, Eymirli A, et al. Dentin moisture conditions affect the adhesion of root canal sealers. J Endod. 2012;38(2):240-244.

25. Sarkar NK, Caicedo R, Ritwik P, Moiseyeva R, Kawashima I. Physicochemical basis of the biologic properties of mineral trioxide aggregate. J Endod. 2005;31(2):97-100.

26. Prüllage RK, Urban K, Schäfer E, Dammaschke T. Material properties of a tricalcium silicate-containing, a mineral trioxide aggregatecontaining, and an epoxy resin-based root canal sealer. $J$ Endod. 2016;42(12):1784-1788.

27. Gurgel-Filho ED, Leite FM, de Lima JB, Chavez Montenegro JP, Saavedra F, Nogueira Leal Silva EJ. Comparative evaluation of pushout bond strength of a MTA-based root canal sealer. Braz J Oral Sci. 2014;13(2):114-117.

28. Silva EJ, Senna PM, De-Deus G, Zaia AA. Cytocompatibility of Biodentine using a three-dimensional cell culture model. Int Endod J. 2016;49(6):574-580.

29. Oliveira AC, Tanomaru JM, Faria-Junior N, Tanomaru-Filho M. Bacterial leakage in root canals filled with conventional and MTA-based sealers. Int Endod J. 2011;44(4):370-375.

30. Hemed SJ, Khalil WM, Saif AI Arab AM. The solubility of a zinc oxide eugenol root canal sealer (Endofil) in normal saline solution at different time intervals. J Bagh College Dentistry. 2005;17(3):4-7. 